\title{
Renal function and histology after acute hemorrhage in rats under dexmedetomidine action ${ }^{1}$
}

\author{
Função e histologia renais após hemorragia aguda em ratos sob \\ ação da dexmedetomidina
}

\author{
Marco Aurelio Marangoni², Alex Hausch ${ }^{3}$, Pedro Thadeu Galvão Vianna ${ }^{4}$, José Reinaldo Cerqueira Braz ${ }^{4}$, Rosa \\ Marlene Viero ${ }^{5}$, Yara Marcondes Machado Castiglia ${ }^{4}$
}

1. Research performed from Experimental Laboratory, Department of Anesthesiology, Medical School, State University of São Paulo (UNESP), Botucatu, Brazil.

2. Fellow PhD degree of Postgraduate Program in Anesthesiology, Medical School, UNESP, Botucatu, Brazil.

3. MD Resident, Department of Anesthesiology, Medical School, UNESP, Botucatu, Brazil.

4. Full Professor, Department of Anesthesiology, Medical School, UNESP, Botucatu, Brazil.

5. PhD, Department of Pathology, Medical School, UNESP, Botucatu, Brazil.

\begin{abstract}
Purpose: About $50 \%$ of indications for dialysis in acute renal failure are related to problems originated during the perioperative period. Intraoperative hemodynamic changes lead to renal vasoconstriction and hypoperfusion. Previous studies have not defined the dexmedetomidine renal role in hemorrhage situations. This study evaluated the effect of dexmedetomidine on renal function and histology after acute hemorrhage in rats. Methods: Covered study with 20 Wistars rats, anesthetized with sodium pentobarbital, $50 \mathrm{mg}$. $\mathrm{kg}^{-1}$, intraperitoneal, randomized into 2 groups submitted to 30\% volemia bleeding: DG - iv dexmedetomidine, $3 \mu \mathrm{g} . \mathrm{kg}^{-1}$ (10 min) and continuous infusion - $3 \mu \mathrm{g} . \mathrm{kg}^{-1}$. h $\mathrm{h}^{-1}$ CG pentobarbital. For renal clearance estimative, sodium p-aminohippurate and iothalamate were administered. Studied attributes: heart rate, mean arterial pressure, rectal temperature, hematocrit, iothalamate and p-aminohippurate clearance, filtration fraction, renal blood flow, renal vascular resistance, and histological evaluations of the kidneys. Results: DG showed smaller values of heart rate, mean arterial pressure, and renal vascular resistance, but iothalamate clearance and filtration fraction values were higher. There was similarity in p-aminohippurate clearance and renal blood flow. Both groups had histological changes ischemia-like, but dexmedetomidine determined higher tubular dilatation scores. Conclusion: In rats, after acute hemorrhage, dexmedetomidine determined better renal function, but higher tubular dilation scores.
\end{abstract}

Key words: Kidney. Hypotension. Dexmedetomidine. Pentobarbital.

\section{RESUMO}

Objetivo: Cerca de 50\% de indicações de diálise em insuficiência renal aguda vêm de problemas do perioperatório. Alterações na hemodinâmica intra-operatória levam a vasoconstrição renal e hipoperfusão. Estudos prévios não definiram o papel renal da dexmedetomidina em hemorragia. Foram estudados os efeitos da dexmedetomidina na função e histologia renais, em ratos, após hemorragia aguda. Métodos: Estudo encoberto com 20 ratos Wistar, anestesiados com pentobarbital sódico intraperitoneal, $50 \mathrm{mg}$. $\mathrm{kg}^{-1}$, divididos aleatoriamente em 2 grupos sob sangramento de 30\% da volemia: GD dexmedetomidina iv, $3 \mu \mathrm{g}$. $\mathrm{kg}^{-1}$ (10 min), e infusão contínua, $3 \mu \mathrm{g}$. kg $\mathrm{g}^{-1}$. h' ; GC - pentobarbital. Para estimar depuração renal, administraram-se para-aminohipurato e iotalamato de sódio. Atributos estudados: freqüência cardíaca, pressão arterial média, temperatura retal, hematócrito, depuração de para-aminohipurato e iotalamato, fração de filtração, fluxo sangüíneo renal, resistência vascular renal, análise histológica dos rins. Resultados: Em GD, houve valores menores de freqüência cardíaca, pressão arterial média e resistência vascular, mas valores maiores de depuração de iotalamato e fração de filtração. A depuração de para-aminohipurato e o fluxo sangüíneo foram similares nos grupos. As alterações histológicas foram compatíveis com isquemia e houve maior dilatação tubular em GD. Conclusão: Em ratos, após hemorragia aguda, a dexmedetomidina determinou melhor função renal, porém maior dilatação tubular.

Descritores: Rim. Hipotensão. Dexmedetomidina. Pentobarbital. 


\section{Introduction}

In cases of acute renal failure, about $50 \%$ of indications for dialysis are related to failures originated during the perioperative period in which high mortality rates still prevail, in spite of better care to the patients. Co-morbidities and advanced age are complicating factors during the evolution of those patients ${ }^{1}$. Acute renal failure during the perioperative period is the result of the exposure of a seriously affected patient to a high risk procedure with nephrotoxic agents infusion, e.g., antibiotics, anesthetics, non-steroidal anti-inflammatory drugs, contrast agents, etc ${ }^{2}$. Other agents responsible for kidney complications are intraoperative hemodynamic changes which lead to renal arteriolar vasoconstriction and parenchyma ischemia by blood flow redistribution. It is well known that factors associated with this process are hypovolemia and hormonal alterations due to endocrine metabolic responses to surgical stress, like the increase in secretion of the antidiuretic hormone, catecholamines, aldosterone, and angiotensin, and the reduction in the atrial natriuretic factor and nitric oxide ${ }^{3}$. Among several $\alpha_{2}$-adrenergic agonists, dexmedetomidine, a dextrogirous enantiomers of medetomidine, which selects $\alpha_{2}: \alpha_{1}$ from $1620: 1$, leads to analgesia and sedation, reduces anesthetics consumption during surgeries ${ }^{4}$, and has analgesic potential good enough to provide analgesia without any opioid utilization $^{5}$. In the kidney, $\alpha_{2}$-adrenergic agonists determine urinary alterations consequent to hemodynamic changes they determine. They reduce the antidiuretic hormone release ${ }^{6}$, or inhibit its action on the distal tubule ${ }^{7}$, inhibit renin release and increase the release of atrial natriuretic peptide ${ }^{8}$. During hypovolemia the role of $\alpha_{2}$-agonist dexmedetomidine in the kidney has not yet been defined. Would dexmedetomidine have a beneficial effect on renal hypoperfusion due to acute hemorrhage? The aim of this study was to evaluate, in rats, the dexmedetomidine action over the renal function and histology after acute hemorrhage.

\section{Methods}

The study was approved by the animal care and ethics committee of our Faculty of Medicine. Adult male Wistar rats ( $>250 \mathrm{~g}$ ) had anesthesia induced with sodium pentobarbital, $50 \mathrm{mg}$. $\mathrm{kg}^{-1}$ by intraperitoneal injection. Two groups of 10 rats each were randomly divided and studied after anesthesia induction and jugular vein cannulation: 1) the dexmedetomidine group (DG), 10 rats submitted to arterial hemorrhage $-30 \%$ of volemia - and to dexmedetomidine - $1 \mu \mathrm{g}$ per $\mathrm{mL}$ of $0.9 \% \mathrm{NaCl}$ with dexmedetomidine velocity infusion of $3 \mu \mathrm{g}$. $\mathrm{kg}^{-1}$ over 10 minutes, followed by continuous infusion of $3 \mu \mathrm{g} . \mathrm{kg}^{-1}$. $\mathrm{h}^{-1}$, i.v.; 2) the control group (CG) 10 rats submitted to the same hemorrhage procedure of DG and the administration of the same volume of $0.9 \% \mathrm{NaCL}$ utilized for dexmedetomidine infusion. The rats were maintained with spontaneous ventilation and supplemental oxygen (2L. min $^{-1}$ ) via a mask. Rectal temperature was monitored with alcohol thermometer. A longitudinal incision in the neck was made with blunt dissection to expose and cannulate with a 24 GA venocath: 1) internal jugular vein to maintain administration of Ringer lactate solution, infused at a rate of $5 \mathrm{~mL}$. kg-1. $\mathrm{h}^{-1}$ to replace lost fluids ${ }^{9}$, and to allow administration of sodium p-aminohippurate (PAH) and sodium iothalamate (IOT) (DG and CG), dexmedetomidine (DG), and $0.9 \% \mathrm{NaCl}(\mathrm{CG}) ; 2$ ) carotid artery for mean arterial pressure and heart rate monitoring via a transducer and recorder (Datex Engstron, Finland) and to collect the $30 \%$ of volemia. Both groups received, immediately after the internal jugular vein cannulation, a loading solution containing $1 \mathrm{mg}$ of PAH (20\%, Sigma, USA) and $0.5 \mathrm{mg}$ of IOT (70 \%, Mallinckrodt, USA) in $0.5 \mathrm{ml} 0.9 \% \mathrm{NaCl}$ infused over $1 \mathrm{~min}$, followed immediately after by a continuous infusion of $1 \mathrm{mg}^{-1} \mathrm{PAH}$ and $0.25 \mathrm{mg}^{-1} \mathrm{~h}^{-1} \mathrm{IOT}$ in $0.9 \%$ $\mathrm{NaCl}$ (Anne infusion pump, Abbot, USA) through the internal jugular vein. Sixty minutes after dexmedetomidine administration in DG and corresponding volume of $0.9 \% \mathrm{NaCl}$ in $\mathrm{CG}$, the $30 \%$ of the volemia were collected in three moments of hemorrhage, with 10 minutes interval between each one, from the animals of both groups. The volemia of the animals was calculated as $6 \%$ of bodyweight. In each moment of hemorrhage, medium arterial pressure, rectal temperature and heart rate were recorded. As the urine flow would not be obtained after the periods of hemorrhage, the clearances of PAH and IOT were estimated through a reliable method for rat model ${ }^{15}$. The arterial blood collected was used for analysis of hematocrit (microhematocrit method, Centremicro, Fanem, Brazil) and concentrations of PAH and IOT by high performance liquid chromatography. The chromatographic system consisted of a Shimatzu Chromatographic (Japan), with a UV detector of wavelenght set at $254 \mathrm{~nm}$, Series SPD $10 \mathrm{AV}$ and an isocratic pump, Series LC $10 \mathrm{AD}$ set at a flow-rate of $0.8 \mathrm{~mL}$. $\mathrm{min}^{-1}$. The mobile phase was methanol-buffer (18:82, v/v). The buffer consisted of $50 \mathrm{mM}$ sodium monobasic phosphate with $0.5 \mathrm{mM}$ tetrabutyl hydrogen sulfate, $0.5 \mathrm{mM}$ sodium monobasic phosphate, $0.5 \mathrm{mM}$ tetrabutyl ammonium hidrogen sulfate with an adjusted $\mathrm{pH}$ 4.11. The column was a $25 \mathrm{~cm} \mathrm{C} 18$ Ominspher reverse phase column purchased from Varian. The guard column containing $5 \mu \mathrm{m}$, C 18 Ominspher purchased from Varian. An auto-injector Series SIL-10A was utilized to inject $20 \mu \mathrm{L}$ of sample with a run time of 30 min. All analysis were performed at room temperature. Stock solutions of PAH and IOT were prepared as $2 \mathrm{mg}$. $\mathrm{mL}^{-1}$ in Mille-Q waters. Stock solutions of acetyl-PAH 
(1mg. $\mathrm{mL}^{-1}$ ) were also made in Mille-Q waters. Standard curve and quality control (QC) samples were freshly prepared for each run. Retention times were: 5.2 min for PAH, 8.7 min for PABA and 11.2 min for IOT. The recovery of $\mathrm{PAH}$ and IOT were $96.4 \%$ and $93.0 \%$ respectively. Two hundred and fifty $\mathrm{mL}$ of serum was transferred into microcentrifuge tubes followed by addition of $500 \mathrm{~mL}$ of acetonitrile containing the internal standard p-aminobenzoic acid $\left(20 \mu \mathrm{L} . \mathrm{mL}^{-1}\right)$. The tubes were vortexed briefly and then centrifuged at 12,000 g for $4 \mathrm{~min}$. The clear supernatant was transferred to vials and $20 \mu \mathrm{L}$ injected into the HPLC system. Clearance (C) was calculated according to Fick's principle: $\mathrm{C}=$ Constant infusion rate (mg. $\left.\mathrm{min}^{-1}\right) /$ Medium arterial concentration (mg. $\left.\mathrm{mL}^{-1}\right)^{10}$. The clearance of PAH $\left(\mathrm{C}_{\mathrm{PAH}}\right)$ was used to estimate the effective renal plasma flow (ERPF) and the clearance of IOT $\left(\mathrm{C}_{\mathrm{IOT}}\right)$ was used to estimate the glomerular filtration rate (GFR). The filtration fraction (FF) was defined as GFR/ ERPF; the renal blood flow (RBF), as ERPF/ (1 - hematocrit); the renal vascular resistance (RVR), as MAP/ RBF. When it was necessary, after each moment of hemorrhage and with MAP lower than $80 \mathrm{mmHg}$, the blood volume collected was replaced by Ringer lactate solution, 1.6 $\mathrm{mL} . \mathrm{kg}^{-1}$. When the periods of blood collection ceased, the rats remained anesthetized during $30 \mathrm{~min}$, and then were sacrificed with overdose of pentobarbital. Both kidneys of each animal were removed for histological analysis and the fresh tissue was fixed during 24 hours in Duboscq-Brasil solution. This solution enhances the reliability of the histological analysis and is prepared with: formol 40\%, $6 \mathrm{~mL}$, absolute alcohol, $12 \mathrm{~mL}$, acetic acid, $1.5 \mathrm{~mL}$, and picric acid in saturated solution. Following this procedure, kidneys were put in alcohol $70 \%$. A full cross-sectional face of each kidney was processed and stained with hematoxylin and eosin. The kidneys were identified by a study number, and the code was not known to the research pathologist who made histological assessments and scores. The attributes studied were heart rate, medium arterial pressure, temperature, hematocrit, effective renal plasma flow, glomerular filtration rate, filtration fraction, renal blood flow, renal vascular resistance, and histological analysis at the following times: M1 - control time (at the time of and with the blood from the $1^{\text {st }}$ hemorrhage); M2 (at the time of the $3^{\text {rd }}$ hemorrhage) -20 minutes after the $1^{\text {st }}$ hemorrhage and 10 minutes after the $2^{\text {nd }}$ hemorrhage, using the blood collected in this $3^{\text {rd }}$ hemorrhage; M3 30 minutes after the $3^{\text {rd }}$ hemorrhage and immediately before the sacrifice of the animal, collecting blood for laboratory analysis (Figure 1). After the preparation of paraffin-fixed laminas from kidneys, they were evaluated for vascular congestion, tubular dilatation, hydropic degeneration, hyaline degeneration, and necrosis. Scores were applied according to the degree of importance for each of possible lesion: 0 , no lesions; 1 , light lesions; 2 , moderate lesions; and 3 , severe lesions.

\section{Statistical analysis}

The weight was analyzed by Student t test to evaluate groups' homogeneity. For traits studied along the time, the profile analysis was used, and for histological variables taken as scores $(0,1,2$, and 3$)$, for each kidney, the comparison between both groups was made by Mann-Whitney non-parametric proof for independent groups, with the $\mathrm{U}$ and p statistical calculus. The scores for both kidneys for each animal were summed and taken as a single result which could vary for each possible histological alteration, from 0 to 6 , in a growing degree of injury. Comparisons between histological changes were restricted to the possible paired events, i.e., it was compared vascular congestion to vascular congestion, and so successively. In all analysis there were significant differences when $\mathrm{P}<0.05$.

$\mathrm{SP}=$ sodium pentobarbital

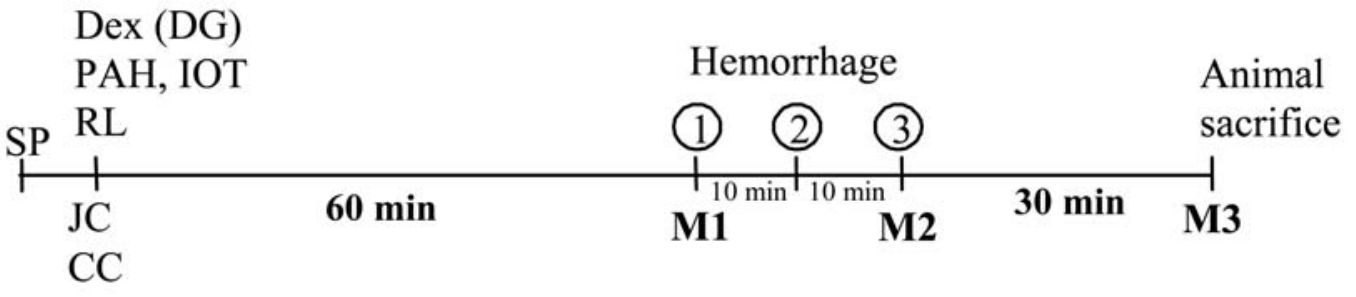

$\mathrm{JC}=$ internal jugular cannulation

$\mathrm{CC}=$ carotid cannulation

$\mathrm{RL}=$ Ringer lactate solution $-5 \mathrm{~mL} \cdot \mathrm{kg}^{-1} \cdot \mathrm{h}^{-1}$

$\mathrm{PAH}, \mathrm{IOT}=\mathrm{PAH}$ and IOT loading solution followed by continuous infusion

Dex (DG) - dexmedetomidine in DG or saline in CG

FIGURE 1 - Experimental sequence 


\section{Results}

Heart rate, mean arterial pressure, and rectal temperature values at M1, M2, and M3, as well as the weight in CG and DG are in Table 1. A significant reduction in heart rate and mean arterial pressure $(\mathrm{p}<$ 0.05 ) occurred in the dexmedetomidine group as compared to controls at all moments. Rectal temperature decreased in both groups during the experimental period $(\mathrm{p}<0.05)$. Data for renal function are described in Table 2. The glomerular filtration rate (IOT clearance) was higher in DG when moments were taken altogether ( $\mathrm{p}<$ 0.05 ), while no difference was detected for effective renal plasma flow (PAH clearance) between groups. The filtration fraction was higher in DG at M2 ( $<<0.05)$. The renal vascular resistance was lower in DG at all moments. There were no differences in renal blood flow and hematocrit values measured at the three moments of the study between groups. Histological evaluation (Table 3) showed abnormalities in both groups. Tubular dilatation (Figure 1) was greater in dexmedetomidine group $(\mathrm{p}<0.05)$ and necrosis was similar in both groups (Figure 2).

TABLE 1 - Baseline values (M1, M2, and M3) in control (CG) and dexmedetomidine (DG) groups

\begin{tabular}{|c|c|c|c|}
\hline & & $\begin{array}{c}\text { CG } \\
(n=10)\end{array}$ & $\begin{array}{c}\text { DG } \\
(n=10)\end{array}$ \\
\hline $\mathrm{MAP}^{\xi}(\mathrm{mmHg})$ & $\begin{array}{l}\text { M1 } \\
\text { M2 } \\
\text { M3 }\end{array}$ & $\begin{array}{l}96,4 \pm 15,5 \\
66,9 \pm 23,5^{*} \\
57,8 \pm 37,5^{*}\end{array}$ & $\begin{array}{l}77,8 \pm 19,8 \\
41,9 \pm 11,0 * \\
32,1 \pm 11,9 *\end{array}$ \\
\hline $\mathrm{HR}^{\xi}(\mathrm{bpm})$ & $\begin{array}{l}\text { M1 } \\
\text { M2 } \\
\text { M3 }\end{array}$ & $\begin{array}{l}236 \pm 28 \\
229 \pm 30 \\
211 \pm 40 *\end{array}$ & $\begin{array}{l}197 \pm 34 \\
177 \pm 27 * \\
146 \pm 49 *\end{array}$ \\
\hline $\mathrm{T}\left({ }^{\circ} \mathrm{C}\right)$ & $\begin{array}{l}\text { M1 } \\
\text { M2 } \\
\text { M3 }\end{array}$ & $\begin{array}{l}33,0 \pm 0,8 \\
31,9 \pm 1,0^{*} \\
31,6 \pm 0,8^{*}\end{array}$ & $\begin{array}{l}32,8 \pm 1,0 \\
31,4 \pm 1,2 * \\
30,9 \pm 1,2 *\end{array}$ \\
\hline W (g) & & $369 \pm 106,9$ & $365 \pm 76,6$ \\
\hline
\end{tabular}

Values are means \pm SE; $n=$ number of animals; MAP, mean arterial pressure; T, rectal temperature; HR, heart rate; W, weight; 3/4 p $<0.05$, CG > DG (moments altogether); * $\mathrm{p}<0.05$ versus M1.

TABLE 2 - Renal function and hematocrit values (M1, M2, and M3) in control (CG) and dexmedetomidine (DG) groups

\begin{tabular}{|c|c|c|c|}
\hline & & $\begin{array}{c}C G \\
(n=10)\end{array}$ & $\begin{array}{l}\text { DG } \\
(n=10)\end{array}$ \\
\hline $\mathrm{C}_{\mathrm{IOT}}^{\xi}(\mathrm{mL} \cdot \mathrm{min}-1)$ & $\begin{array}{l}\text { M1 } \\
\text { M2 } \\
\text { M3 }\end{array}$ & $\begin{array}{r}7,56 \pm 3,55 \\
5,679 \pm 2,73 \\
6,354 \pm 3,11\end{array}$ & $\begin{array}{r}9,59 \pm 5,68 \\
10,70 \pm 3,93 \\
9,83 \pm 4,73\end{array}$ \\
\hline СРAH (mL.min-1) & $\begin{array}{l}\text { M1 } \\
\text { M2 } \\
\text { M3 }\end{array}$ & $\begin{array}{l}25,00 \pm 4,40 \\
25,21 \pm 3,72 \\
25,28 \pm 5,33\end{array}$ & $\begin{array}{l}27,63 \pm 3,70 \\
27,01 \pm 3,93 \\
25,84 \pm 4,23\end{array}$ \\
\hline $\mathrm{FF}$ & $\begin{array}{l}\text { M1 } \\
\text { M2 } \\
\text { M3 }\end{array}$ & $\begin{array}{l}0,33 \pm 0,23 \\
0,24 \pm 0,15 \\
0,28 \pm 0,19\end{array}$ & $\begin{array}{l}0,36 \pm 0,23 \\
0,41 \pm 0,19 \\
0,40 \pm 0,24\end{array}$ \\
\hline $\mathrm{RVR}^{\&}\left(\mathrm{mmHg} \cdot \mathrm{min}^{-1} \cdot \mathrm{mL}^{-1}\right)$ & $\begin{array}{l}\text { M1 } \\
\text { M2 } \\
\text { M3 }\end{array}$ & $\begin{array}{l}2,22 \pm 0,59 \\
1,60 \pm 0,47^{*} \\
1,39 \pm 0,71^{*}\end{array}$ & $\begin{array}{l}1,60 \pm 0,40 \\
0,98 \pm 0,30 * \\
0,79 \pm 0,25 *\end{array}$ \\
\hline $\mathrm{RBF}\left(\mathrm{mL} \cdot \mathrm{min}^{-1}\right)$ & $\begin{array}{l}\text { M1 } \\
\text { M2 } \\
\text { M3 }\end{array}$ & $\begin{array}{l}44,62 \pm 8,17 \\
41,51 \pm 6,00 \\
40,06 \pm 8,90\end{array}$ & $\begin{array}{l}49,13 \pm 6,84 \\
44,00 \pm 6,55 \\
40,12 \pm 6,78^{*}\end{array}$ \\
\hline Ht (\%) & $\begin{array}{l}\text { M1 } \\
\text { M2 } \\
\text { M3 }\end{array}$ & $\begin{array}{l}43,8 \pm 3,0 \\
39,3 \pm 1,6 * \\
36,7 \pm 2,1^{*}\end{array}$ & $\begin{array}{l}43,7 \pm 2,8 \\
38,6 \pm 2,0^{*} \\
35,6 \pm 2,1^{*}\end{array}$ \\
\hline
\end{tabular}

Values are means $\pm \mathrm{SE} ; n=$ number of animals; CIOT, clearance of iothalamate; CPAH, clearance of paminohippurate; FF, filtration fraction; RVR, renal vascular resistance; RBF, renal blood flow. 3/4 p < 0.05, CG $<$ DG (moments altogether); \# p $<0.05$, CG $<$ DG; \& p $<0.05$, CG $>$ DG; * p $<$ 0.05 versus M1. 
TABLE 3 - Score sum of right and left kidney histological changes of control (CG) and dexmedetomidine (DG) groups

\begin{tabular}{|l|l|l|l|l|l|l|l|l|l|l|l|l|l|l|l|l|l|l|l|l|}
\hline Group & & & & & CG & & & & & & & & & & DG & & & & \\
\hline Rat & $\mathbf{1}$ & $\mathbf{2}$ & $\mathbf{3}$ & $\mathbf{4}$ & $\mathbf{5}$ & $\mathbf{6}$ & $\mathbf{7}$ & $\mathbf{8}$ & $\mathbf{9}$ & $\mathbf{1 0}$ & $\mathbf{1 1}$ & $\mathbf{1 2}$ & $\mathbf{1 3}$ & $\mathbf{1 4}$ & $\mathbf{1 5}$ & $\mathbf{1 6}$ & $\mathbf{1 7}$ & $\mathbf{1 8}$ & $\mathbf{1 9}$ & $\mathbf{2 0}$ \\
\hline $\begin{array}{l}\text { Histological } \\
\text { analysis }\end{array}$ & & & & & & & & & & & & & & & & & & \\
\hline $\begin{array}{l}\text { Vascular } \\
\text { congestion }\end{array}$ & $2+$ & $1+$ & & & $5+$ & $2+$ & $3+$ & & & $2+$ & & $3+$ & $2+$ & $2+$ & $4+$ & $2+$ & $2+$ & $2+$ & $2+$ \\
\hline $\begin{array}{l}\text { Tubular } \\
\text { dilatation* }\end{array}$ & & & & $3+$ & $4+$ & $2+$ & $2+$ & $2+$ & $1+$ & & $4+$ & $3+$ & $4+$ & $4+$ & $3+$ & $3+$ & $3+$ & $2+$ & $2+$ & $2+$ \\
\hline $\begin{array}{l}\text { Hydropic } \\
\text { degeneration }\end{array}$ & $3+$ & $3+$ & $2+$ & $2+$ & $2+$ & $2+$ & $2+$ & $2+$ & $2+$ & $3+$ & $2+$ & $2+$ & $2+$ & $1+$ & $1+$ & $1+$ & $1+$ & $2+$ \\
\hline $\begin{array}{l}\text { Hyaline } \\
\text { degeneration }\end{array}$ & $3+$ & $2+$ & $2+$ & $2+$ & $2+$ & & & & & & & & & $2+$ & $2+$ & $4+$ & $2+$ & $2+$ & $2+$ & $2+$ \\
\hline \begin{tabular}{l} 
Necrosis \\
\hline
\end{tabular}
\end{tabular}

$* \mathrm{p}<0.05, \mathrm{CG}<\mathrm{DG}$

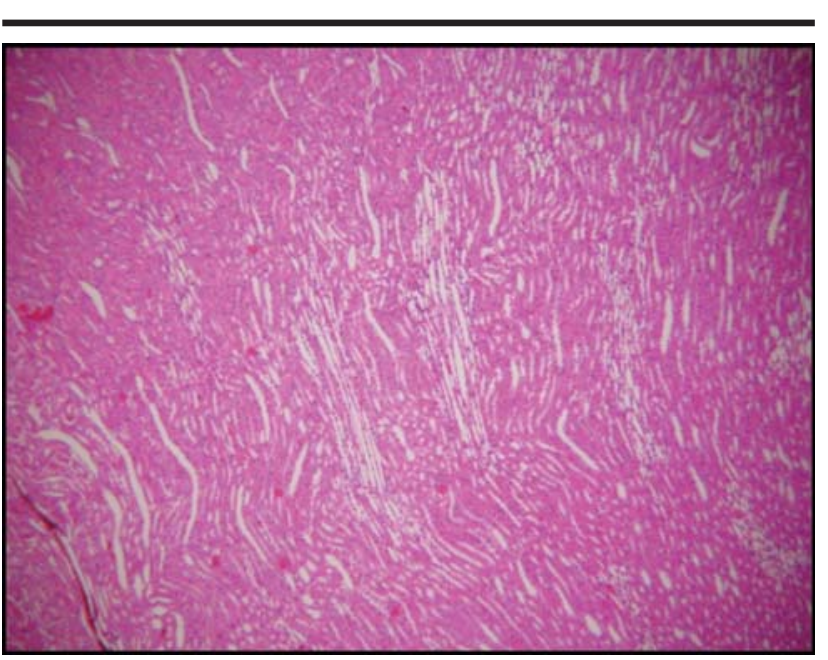

FIGURE 2 - Hemorrhage of $30 \%$ of volemia produced, 30 minutes after, dilated tubules in the cortex kidney of rats anesthetized with sodium pentobarbital (control group - CG) and receiving dexmedetomidine intravenous (DG). Histopathological examination shows renal tubule of DG rat. DG > CG $(\mathrm{p}<0.05$, Mann-Whitney test)

\section{Discussion}

Dexmedetomidine causes a dose-dependent decrease in heart rate immediately after the onset of administration, mainly as a consequence of the decrease in sympathetic tonus ${ }^{11,12}$. The decrease in CG heart rate occurred just 50 min after the onset of hemorrhage. Sodium pentobarbital was used for anesthesia because it stabilizes cardiovascular conditions, what is very important for an experimental model of kidney ischemia ${ }^{13}$. As its lack of effects on kidney functions has been already proved, the alterations can be attributed to the experimental model ${ }^{13}$. Volunteers showed a decrease in heart rate after have been administered

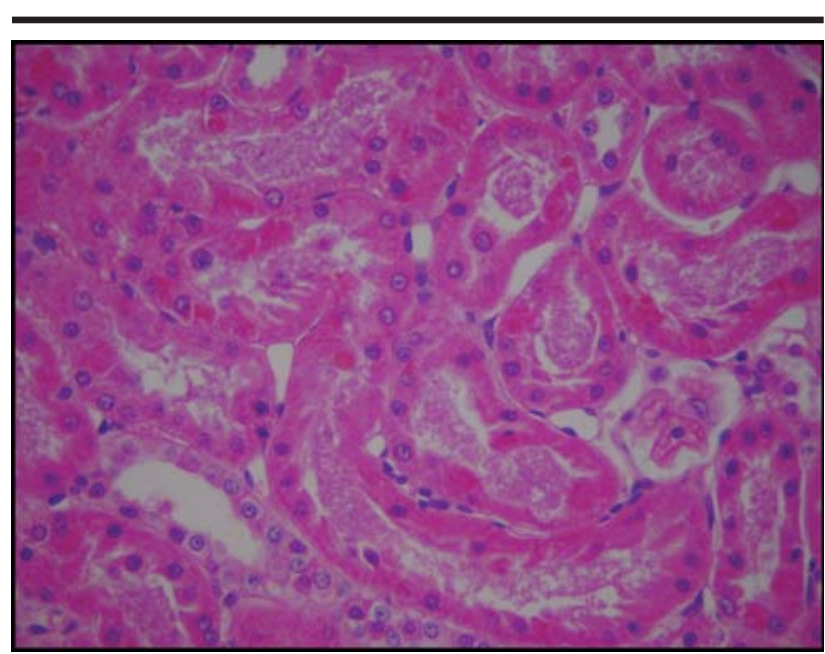

FIGURE 3 - Hemorrhage of $30 \%$ of volemia produced, 30 minutes after, tubular necrosis in the kidney of rats anesthetized with sodium pentobarbital (control group - CG) and receiving dexmedetomidine intravenous (DG). Histopathological examination shows kidney of DG rat. DG = CG ( $>$ > 0,05, MannWhitney test)

dexmedetomidine, subsequently to an increase in mean arterial pressure, revealing that the baroreflex activation is one of the mechanisms involved in heart rate decrease ${ }^{14}$. Therefore, slow infusion of the initial dose of dexmedetomidine is recommended. Another possible reason for heart rate decrease is the lowering of plasma norepinephrine concentrations ${ }^{4}$. As for mean arterial pressure, lower values were observed in DG, but CG also showed a progressive decrease probably due to hemorrhage. Changes in arterial pressure resulting from $\alpha_{2}$-adrenergic action indicate a biphasic dose-dependent response. Clinical doses lead to a decrease in arterial pressure mainly due to a sympatholitic effect. In man, low plasma dexmedetomidine concentrations ( 0.7 to 1.2 
ng. $\mathrm{mL}^{-1}$ ) tend to reduce mean arterial pressure, while higher concentrations (above 1.9 ng. $\mathrm{mL}^{-1}$ ) tend to elevate it because its action prevails on peripheral á adrenergic receptors ${ }^{4,14}$. The ability of changing the thermoregulatory response by á action has been demonstrated. Dexmedetomidine is able to originate an intense hypothermia in mice mediated, mainly, by affinity for $\alpha_{2 a}$-receptors, and causes a decrease in norepinephrine, dopamine and serotonin release in the central nervous system ${ }^{15}$. Hypothermia was found in both groups during the experimental procedure. Sodium pentobarbital leads to hypothermia ${ }^{16}$, which was observed in CG at M1. However, assuming that hypothermia is protective to kidney function when perfusion is lowering ${ }^{17}$, this event could have interfered with the analysis of kidney function in rats, had it not occurred in both groups. During hemorrhage, hematocrit decreased equally within each group. A large reduction in hematocrit values, immediately after hemorrhage, is not expected, for this event only occurs when the intravascular bed absorbs liquid from the interstitial compartment to improve circulating volume. However, the hemorrhage and simultaneous infusion of crystalloid solution, dexmedetomidine saline solution or saline solution alone (depending upon the group studied), and other agents (sodium iothalamate and sodium paminohippurate) also diluted in saline solution, allowed a fast identification of this erythrocyte mass loss. Among the several prostaglandins (PGs) secreted by the kidney, $\mathrm{PGE}_{2}$ and $\mathrm{PGI}_{2}$ show vasodilatation activity. Physiological concentrations of PGs are very low. When either kidney sympathetic activity or angiotensin II levels are increased, the synthesis and release of dilatating PGs also increase with consequent activity on afferent and efferent arteriolae and on glomerular (mesangial) cells as well. As a result, the vasoconstrictor role of norepinephrine and angiotensin II are counterbalanced by PGs vasodilatation activity, leading to a less intense change in kidney vascular resistance ${ }^{9}$. The advantage of such adaptation originated by opposite stimuli would be the balance between the requirement of the increased total peripheral resistance for maintenance of systemic arterial pressure (which favours heart and encephalus), and the probability of kidney injury, in case of vasoconstriction in the organ be very intense ${ }^{18}$. In dogs, there was an increase in kidney PGs after injection of 20 ìg. $\mathrm{kg}^{-1}$ clonidine, which could explain the protective potential of $a_{2}$-agonists to the kidneys. It seems that these agents, besides leading to vasodilatation, are involved in the inhibition of aldosterone, as the use of dexmedetomidine has already demonstrated ${ }^{19}$. The glomerular filtrate is essentially protein free and contains many inorganic ions and low molecular weight organic solutes in virtually the same concentrations found in plasma. The hydraulic pressure (hydrostatic) in glomerular capillary (GCP) reflects the dynamics between kidney arterial pressure, afferent arteriolar resistance (AR) and efferent arteriolar resistance (ER). Furthermore, GCP is one of the forces that induce glomerular filtration. Any alteration in kidney arterial pressure tends to cause an alteration in the same direction in GCP, though minimal. On the other hand, for a given kidney arterial pressure, an increase in AR (by afferent arteriolar constriction) tends to decrease GCP, simply by determining a great loss of pressure between kidney arteries and glomerular capillaries. On the contrary, a decrease in AR (by afferent arteriolar dilatation) tends to elevate GCP. Yet, and more difficult to measure, changes in ER tend to originate changes in GCP, but these changes are opposite to those determined by changes in AR. In this way, increases in ER (by efferent arteriolar constriction) is likely to increase GCP because the efferent arteriola remains beyond the glomerulus, so that its constriction tends to cause a blood reflow in glomerular capillaries, increasing GCP. In a similar way, a decrease in ER (by efferent arteriolar dilatation) tends to decrease $\mathrm{GCP}^{18}$. Animals of DG and CG showed a significant decrease in mean arterial pressure, permitting to suggest a decrease in glomerular capilar hydraulic pressure and, as a consequence, also in glomerular filtration rate. However, this was only observed in DG. In this group, glomerular filtration rate was always greater than in CG, suggesting that an increase in afferent arteriolar resistance (at least isolated) had not occurred, or there would have been a decrease in glomerular capilar hydraulic pressure. Nevertheless, a possible increase in efferent arteriolar resistance might have taken place, determining an increase in glomerular capilar hydraulic pressure, as well as in glomerular filtration rate. There was no difference between the effective renal plasma flow of CG and DG. However, it is worthy to emphasize that cardiac output is a fundamental factor to renal plasma flow and depends on heart rate. As the latter remained low in DG, a decrease in effective renal plasma flow would be expected, but this did not occur. So, it is suggested that $\mathrm{a}_{2}$-agonists have the ability of preserving kidney perfusion in a situation similar to that found in this study, i.e., hemorrhage followed by hypotension. In this study of hypotension as a consequence of hemorrhage, three factors which could reduce effective renal plasma flow (and, to a lesser degree, glomerular filtration rate) in CG must be considered - the decrease in mean arterial pressure, kidney sympathetic innervation and angiotensin II. Simultaneously, two factors would minimize effective renal plasma flow reduction - kidney autoregulation and kidney prostaglandins, which are released through sympathetic and angiotensin II stimulation ${ }^{18}$. In this work, animals showed a significant decrease in kidney vascular resistance. There was an increase in filtration fraction at M2, the moment of the third hemorrhage, when rats had been already subjected to a $20 \%$ loss in volemia. This result is different from 
those of other studies which take the increase in urinary output, caused by á ${ }_{2}$-agonists, as a consequence of the increase in free water excretion, due to the reduction of antidiuretic hormone release or action, with no evidences of increase in the filtration fraction ${ }^{14}$. When kidney vascular resistance was compared in DG and CG, a significant decrease was observed at all moments, the same occurring between moments considered inside each group. Dexmedetomidine group always showed lower values than control group. The arterial resistance is determined by blood viscosity and by the length and diameter of blood vessels. Arteriolar diameter is the principal factor in the arterial resistance and is determined by arteriolar smooth muscle contraction. In the kidney, the existence of two arteriola sets and two capillary sets turns the renal vascular resistance unique. Normally, resistance of afferent and efferent arteriola is approximately the same and is the main vascular resistance of the organ. For a normal filtration, the development of a high glomerular hydraulic pressure is needed, while the peritubular low capillary pressure is equally crucial for the tubular fluid reabsorption ${ }^{18}$. Dexmedetomidine increased GFR and decreased renal vascular resistance in DG. So, this agent was likely to provoke afferent arteriolar vasodilatation and efferent arteriolar vasoconstriction. In spite of the diminished blood pressure occurred after dexmedetomidine infusion, which could lead to renal hypoperfusion, that change in the arteriolar tonus permitted renal blood flow to remain stable. The renal histological analysis showed higher tubular dilatation in DG, but these animals have been submitted to worse hemodynamic state in our experimental model (hemorrhage and arterial hypotension due to dexmedetomidine). The renal vascular congestion observed in DG was higher than in CG, although the difference was not significant. This higher renal vascular congestion is compatible with the $a_{2}$-agonist action that diminishes heart rate, blood pressure, and renal vascular resistance. The hydropic and hyaline degenerations, and the necrosis have been observed in both groups, but they were similar. Severe and prolonged hypotension and consequent renal hypoperfusion ultimately leads to ischemic acute tubular necrosis ${ }^{20}$. The ischemia caused by hypovolemia often results in renal failure and cell death will occur due to a series of metabolic disturbances. The cell death is observed either as necrosis or apoptosis in experimental model of renal injury both in vivo and in vitro. Cellular necrosis results from the combined deleterious effects of a number of biochemical pathways precipitated by severe injury to the cell ${ }^{21}$ and there is widespread cellular degradation. Ischemic kidneys suffer deep losses of adenosine triphosphate owing to reduced availability of oxygen and nutrients causing inhibition of both oxidative phosphorylation and anaerobic glycolysis. Some cells die during ischemia itself, mostly by early necrosis and the damage of membrane leads to activation of multiple degradative systems in an uncontrolled way. Necrosis is observed predominantly in proximal tubules of the kidney, which use mitochondrial respiration as the sole source for their energy requirements ${ }^{22}$. Therefore, these segments of nephron are more prone to ischemic insults during the initial stages. The severity and duration of ischemia required to lead to acute renal failure in humans are unknown. There is an interval that operationally defines the transition from functional pre-renal to fixed post-ischemic ARF. The recovery of renal blood flow by volume expansion or vasodilators restores renal function during the functional stage but not after the establishment of fixed $\mathrm{ARF}^{23}$. Tubular necrosis was observed in dog kidneys submitted to 30 minutes of total ischemia ${ }^{13}$. Our rats remained with hypotension due to hemorrhage during an experimental period of 50 minutes. In summary, with acute blood loss, dexmedetomidine reduced renal vascular resistance and increased glomerular filtration rate and filtration fraction, promoting histological changes consistent with answer to ischemia, but with tubular dilatation more intense than that of the control group.

\section{Conclusion}

In rats, after acute hemorrhage, dexmedetomidine determined better renal function, but higher tubular dilation scores.

\section{References}

1. Levy EM, Viscoli CM, Horwitz RI. The effect of acute renal failure on mortality: a cohort analysis. J Am Med Assoc.1996; 275:1489-94.

2. Weldon BC, Monk TG. The patient at risk for acute renal failure. Anesthesiol Clin North Am. 2000;18:705-17.

3. Lema G, Canessa R, Urzua J. Renal preservation in cardiac surgery. Curr Opin Anesthesiol. 1998;11:9-13.

4. Ebert TJ, Hall JE, Barney JA, Uhrich TD, Colinco MD. The effects of increasing plasma concentrations of dexmedetomidine in humans. Anesthesiology. 2000;93:382-94.

5. Marangoni MA, Castiglia YMM, Medeiros TP. Analgesic efficacy of dexmedetomidine as compared to sufentanil in intraperitoneal surgeries: comparative study. Rev Bras Anestesiol. 2005;55:19-27.

6. Cabral AD, Kapusta DR, Keniqs VA, Varner KJ. Central $\mathrm{a}_{2}$-receptor mechanisms contribute to enhanced renal responses during ketamine-xylazine anesthesia. Am J Physiol. 1998;275 (6 Pt 2):R1867-74. 
7. Gellai M. Modulation of vasopressin antidiuretic action by renal alpha 2-adrenoceptors. Am J Physiol. 1990;259(1 Pt 2):1-8.

8. Maze M, Tranquilli W. Alpha-2 adrenoceptor agonists: defining the role in clinical anesthesia. Anesthesiology. 1991;74:581-605.

9. Silva MS, Castiglia YMM, Vianna PTG, Viero RM, Braz JRC, Cassetari ML. Rat model of depending prostaglandin renal state: effect of ketoprofen. Ren Fail. 2006;28:77-84.

10.Rönnhedh C, Jaquenod M, Mather LE. Urineless estimation of glomerular filtration rate and renal plasma flow in the rat. J Pharmacol Toxicol Meth. 1996;36:123-9.

11. Talke P, Chen R, Thomas B, Aggarwall A, Gottlieb A, Thorborg P, Heard S, Cheung A, Son SL, Kallio A. The hemodynamic and adrenergic effects of perioperative dexmedetomidine infusion after vascular surgery. Anesth Analg. 2000;90:834-9.

12.Engelhard K, Werner C, Kaspar S, Mollenberg O, Blobner M, Bachl M, Kochs E. Effects of the alpha2agonist dexmedetomidine on cerebral neurotransmitter concentrations during cerebral ischemia in rats. Anesthesiology. 2002;96:450-7.

13. Módolo NSP, Castiglia YM, Ganem EM, Braz JR, Vianna PT, Vane LA. Acute renal ischemia model in dogs: effects of metoprolol. Ren Fail. 2001;23:1-10.

14.Dyck JB, Maze M, Haack C, Vuorilehto L, Shafer SL. The pharmacokinetics and hemodynamic effects of intravenous and intramuscular dexmedetomidine hydrochloride in adult human volunteers. Anesthesiology. 1993;78:813-20.

15.Lahdesmaki J, Sallinen J, MacDonald E, Sirvio J, Scheinin M. Alpha2-adrenergic drug effects on brain monoamines, locomotion, and body temperature are largely abolished in mice lacking the alpha2Aadrenoceptor subtype. Neuropharmacology. 2003;44:882-92.

16. Castiglia YM, Braz JR, Vianna PT, Lemonica L, Vane LA. Effect of high dose fentanyl on renal function in dogs. Sao Paulo Med J. 1997;115:1433-9.

17.Zager RA, Altschuld R. Body temperature: an important determinant of severity of ischemic renal injury. Am J Physiol. 1986;251(1 Pt 2):F87-93.

18. Vander AJ. Renal physiology. New York: McGrawHill Inc. Health Professions Division; 1995.

19. Rouch AJ, Kudo LH. Alpha2-adrenergic-mediated inhibition of water and urea permeability in the rat inner medullary collecting duct. Am J Physiol. 1996;271(1 Pt 2):F150-7.

20. Rusafa Neto E, Vianna PTG, Viero RM, Módolo NSP, Braz JRC, Castiglia YMM. Influence of S(+)-ketamine analgesia in renal intraoperative inschemia: histological study in rats. Acta Cir Bras. 2006;21:242-6.

21.Lieberthal W, Koh JS, Levine JS. Necrosis and apoptosis in acute renal failure. Semin Nephrol 1998;18:505-18.

22. Wirthensohn G, Guder WG. Renal substrate metabolism. Physiol Rev. 1986;66:469-97.

23. Lameire N, Vanholder R. Pathophysiology of ischaemic acute renal failure. Best Pract Res Clin Anaesthesiol. 2004;18:21-36.

\section{Acknowledgment}

Maria Luiza Cassetari, Biologist of Public Health Department of Medical School of Botucatu.

\section{Correspondence:}

Yara M. M. Castiglia

Department of Anesthesiology, Medical School - UNESP

Distrito Rubião Junior, s/n

Caixa Postal 530

18618-970 Botucatu - SP Brazil

Phone: (55 14)3811-6222

Fax:: (55 14)3811-6061

yarac@fmb.unesp.br
Conflict of interest: none Financial source: none

Received: March 19, 2007

Review: May 15, 2007

Accepted: June 14, 2007

\section{How to cite this article}

Marangoni MA, Hausch A, Vianna PTG, Braz JRC, Viero RM, Castiglia YMM. Renal function and histology after acute hemorrhage in rats under dexmedetomidine action. Acta Cir Bras. [serial on the Internet] 2007 July-Aug;22(4). Available from URL: http://www.scielo.br/acb 